DOI: http://dx.doi.org/10.15688/jvolsu4.2016.3.15

UDC $327(470+571)$

Submitted: 18.01 .2016

LBC 66.2(2Poc)

Accepted: 26.05 .2016

\title{
CONCEPTUAL DIMENSION OF PROBLEMS OF JOINT ACTIVITY OF THE STATE AND CIVIL SOCIETY INSTITUTES ON ENSURING NATIONAL SECURITY OF THE RUSSIAN FEDERATION
}

\author{
Vyacheslav N. Gulyaikhin \\ Volgograd State University, Volgograd, Russian Federation \\ Pavel P. Fantrov \\ Volgograd State University, Volgograd, Russian Federation
}

\begin{abstract}
In the article the main methodological approaches to the problem of interaction of institutes of the state and civil society in the context of ensuring national security of Russia are analyzed. Two main alternative concepts (liberal and etatist) to which the Russian researchers adhere are allocated. Supporters of liberal approach suppose that domination of the interests of civil society and ensuring equal cooperation with government institutions at the solution of problems of ensuring national security is necessary. Adherents of the etatist concept defend an unconditional priority of government bodies in this sphere. The authors provide the conceptual analysis of estimates by domestic researchers of the main activities of associations of the citizens connected with the counteraction to threats of national security. In the article positive impact of institutes of civil society on political and social and economic processes in Russia is noted, their assistance in development of the state institutes of the state and the potential of constructive interaction with federal and regional authorities on ensuring national security is estimated. The detailed analysis of the politological concept according to which more active participation of public organizations and socially responsible citizens in ensuring national security is necessary, is carried out. Their influence on development of a security system has to become more and more considerable because of social and economic problems which are objectively demanding participation of civil society in their decision-making. It is connected also with the need of modernization breakthrough, not possible without civil initiatives. In the article the conclusion that the Russian researchers attach great value to interaction of institutes of the state and civil society in ensuring national security of the Russian Federation is drawn, conceptually proving the need of their joint activity for this direction, and noting that this potential is still not fully realized.

Key words: national security, civil society, state institute, liberalism, etatism.

УДК $327(470+571)$

Дата поступления статьи: 18.01.2016

ББК $66.2(2 \mathrm{Poc})$

Дата принятия статьи: 26.05.2016

КОНЦЕПТУАЛЬНОЕ ИЗМЕРЕНИЕ ПРОБЛЕМ СОВМЕСТНОЙ ДЕЯТЕЛЬНОСТИ ИНСТИТУТОВ ГОСУДАРСТВА И ГРАЖДАНСКОГО ОБЩЕСТВА ПО ОБЕСПЕЧЕНИЮ НАЦИОНАЛЬНОЙ БЕЗОПАСНОСТИ РФ
\end{abstract}

\author{
Вячеслав Николаевич Гуляихин \\ Волгоградский государственный университет, г. Волгоград, Российская Федерация
}




\section{Павел Петрович Фантров}

Волгоградский государственный университет, г. Волгоград, Российская Федерация

Аннотация. В статье проанализированы основные методологические подходы к исследованию проблемы взаимодействия институтов государства и гражданского общества в контексте обеспечения национальной безопасности России. Выделены две основные альтернативные концепции (либеральная и этатистская), которых придерживаются российские исследователи. Для сторонников либерального подхода является необходимым доминирование интересов гражданского общества и обеспечение равноправного сотрудничества с государственными структурами при решении проблем обеспечения национальной безопасности. Приверженцы этатистской концепции отстаивают безусловный приоритет государственных органов в данной сфере. Авторами дан концептуальный анализ оценок отечественными исследователями основных направлений деятельности ассоциаций граждан, связанных с противодействием угрозам национальной безопасности. В статье отмечено позитивное воздействие институтов гражданского общества на политические и социально-экономические процессы в России, их содействие в развитии институтов государства и оценен потенциал конструктивного взаимодействия с федеральными и региональными органами власти по обеспечению национальной безопасности. Проводится детальный анализ политологической концепции, в соответствии с которой необходимо более активное участие общественных организаций и социально ответственных граждан в деле обеспечения национальной безопасности, а также повышение политического значения институтов гражданского общества. Их влияние на развитие системы безопасности должно становиться все более значительным, поскольку усиливаются социально-экономические проблемы, объективно требующие участия гражданского общества в их решении. Это связано также с необходимостью модернизационного прорыва, невозможного без гражданских инициатив. В статье сделан вывод о том, что российские исследователи придают большое значение взаимодействию институтов государства и гражданского общества в деле обеспечения национальной безопасности РФ, концептуально обосновывают необходимость их совместной деятельности в этом направлении и отмечают, что данный потенциал реализуется еще далеко не в полной мере.

Ключевые слова: национальная безопасность, гражданское общество, государственный институт, либерализм, этатизм.

В последнее время Россия сталкивается с нарастающими угрозами ее безопасности, становится все более актуальным поиск новых резервов для ее обеспечения. Одним из таких ресурсов, еще не получившим должного признания своего потенциала со стороны государства с целью его использования в системе национальной безопасности, являются институты гражданского общества. Значительная их часть функционирует в качестве центростремительных сил, направленных на укрепление социальных связей между различными общественно-политическими составляющими российского социума. Они являются важной составляющей гражданского общества, которое представляет собой систему добровольно сформированных объединений и организаций. В определенной степени деятельность данных ассоциаций и общественных структур независима от государственной власти (она регулируется сложившимися политическими традициями и действующей нормативно-правовой базой) и направлена на решение социально значимых задач, в том чис- ле связанных с обеспечением национальной безопасности.

Проблема совместной деятельности институтов гражданского общества и государства по обеспечению национальной безопасности требует концептуального углубления ее анализа. Исходным принципом здесь может выступить тезис А.В. Шиловцева о том, что для безопасного цивилизационного развития политической системы современное государство должно обеспечить открытую обратную связь со структурами гражданского общества $[24$, с. 236]. Ведь без них вряд ли возможно ее полноценное обеспечение. Соответственно, ресурс влияния институтов гражданского общества на повышение уровня национальной безопасности «мог бы быть гораздо выше, чем это имеет место в настоящее время» $[14$, с. 227].

Участие общественных организаций и социально ответственных граждан в обеспечении национальной безопасности позволит избежать усиливающегося отчуждения между государственными учреждениями и ин- 
ститутами гражданского общества. Осознание объективной необходимости этого окажет позитивное влияние как на позицию самих государственных структур (чьи руководители зачастую настороженно относятся к деятельности независимых общественных объединений), включенных в систему безопасности, так и на настроения значительной части российских граждан, стимулируя их к солидаризации, самоорганизации и созданию общественных ассоциаций для того, чтобы защитить жизненно важные интересы российского суперэтноса [22, с. 103]. Институты гражданского общества должны занять ключевые места в обеспечении национальной безопасности страны. Этот концептуальный подход следует рассматривать как более приемлемый для современного состояния российского общества, по-настоящему демократический вариант регулирования российской властью многомерного социальнополитического пространства в целях обеспечения его безопасности.

Идея налаживания тесного взаимодействия органов власти с институтами гражданского общества, имеющими необходимый потенциал в предотвращении угроз национальной безопасности и достижении высокого уровня защищенности национальных интересов, представляется вполне возможной в условиях нарастания современного социальноэкономического кризиса. Гражданское общество заключает в себе значительный потенциал для формирования ценностей гражданского мира и согласия, необходимых для обеспечения устойчивого развития страны. В российском обществе политическое значение институтов гражданского общества должно становится все более значительным, поскольку усиливаются социально-экономические проблемы, объективно требующие их участия в решении острых вопросов, связанных с необходимостью модернизационного прорыва [9, с. 84-85]. Уровень социально-политической ответственности должен постепенно смещаться от государственных структур в их сторону. Поскольку «с учетом уровня образования, политической, социальной активности определенной части общества, можно утверждать, что уровень влияния на формирование мнений и настроений в обществе у ин- ститутов гражданского общества велик. И это подтверждает статистика, россияне достаточно активно пользуются услугами НКО и НПО, в год количество обращений в эти структуры составляет примерно 12-13 \% населения России» [12, с. 217].

Отечественные исследователи выделяют ряд направлений деятельности ассоциаций граждан, связанных с противодействием угрозам национальной безопасности:

- позитивное воздействие на политические и социально-экономические процессы в России (например, участие в военнопатриотическом воспитании молодежи, благотворительная деятельность, волонтерское движение);

- содействие в развитии государственных институтов (общественные палаты в субъектах РФ; общественные комиссии, созданные при государственных учреждениях; общественная экспертиза);

- конструктивное взаимодействие с федеральными и региональными органами власти по обеспечению национальной безопасности (народные дружины по охране правопорядка, добровольные казачьи формирования);

- выявление национальных интересов, политических целей и социальных ценностей граждан, а также оказание им помощи в определении собственной стратегии общественно полезной деятельности (религиозные организации, политические партии, спортивные объединения) [6, с. 67-68].

Институты гражданского общества и государства способны совместно бороться со следующими угрозами национальной безопасности России: усилением межэтнической и межнациональной напряженности, криминализацией общественных отношений, экстремизмом и терроризмом, ксенофобией и национализмом, социально-экономическими проблемами, снижением уровня физического здоровья населения, ухудшением экологической ситуации [19, с. 149-150].

Рассматривая юридические аспекты претворения в жизнь концепции национальной безопасности, Ю.С. Порхунова предлагает закрепить соответствующие полномочия за органами местной власти, разделив решение задач в области ее обеспечения органами местного самоуправления на прямо- и кос- 
веннонаправленные. К числу «прямых» задач органов местного самоуправления она относит следующие: профилактику, минимизацию социальной напряженности, нивелирование экстремизма и ксенофобии, осуществление мероприятий по гражданской обороне, участие в ликвидации последствий чрезвычайных ситуаций, организацию и осуществление мероприятий по обеспечению первичных мер пожарной безопасности, реализацию мероприятий по мобилизационной подготовке муниципальных учреждений. К числу задач национальной безопасности, косвенно способствующих ее обеспечению, она относит: социальную поддержку малоимущих граждан и улучшение их жилищных условий, создание необходимых условий для жилищного строительства, организацию досуга жителей муниципального района и их обеспечение услугами учреждений культуры, сохранение и популяризацию объектов культурного наследия, охрану объектов культурного наследия местного значения, организацию и проведение официальных спортивных и физкультурно-оздоровительных мероприятий, реализацию мероприятий по работе с детьми и молодежью, содействие в трудоустройстве граждан, обеспечение занятости несовершеннолетних граждан в возрасте от 14 до 18 лет, оказание содействия национально-культурному развитию народов РФ. Таким образом, Ю.С. Порхунова придает весьма большое значение деятельности органов местного самоуправления по обеспечению национальной безопасности, отнеся большую часть их функций к ее области.

Свое концептуальное обоснование получила необходимость усиления роли общественных объединений в сохранении межнационального мира и согласия, а также в противодействии попыткам ослабления государственного единства российского федеративного государства, предотвращении этнической и религиозной вражды [4, с. 22]. В 2012 г. была утверждена «Стратегия государственной национальной политики России», в обсуждении которой активно участвовала Общественная палата Российской Федерации. Стратегическими задачами были признаны как сбережение уникальности и самобытности каждого этноса, так и утверждение идеи надэтничес- кого гражданского единства в сознании российского суперэтноса. Общественные организации были призваны осуществлять деятельность, направленную на преодоление межэтнической разобщенности, особенно в молодежной среде. Их целью должны стать создание условий и поддержка общественной активности в деятельности, повышающей уровень межэтнического взаимодействия, развиваемого на принципах патриотизма [5, с. 37]. Национально-культурные автономии и органы государственной власти должны иметь общую цель - укрепление государственности, что подразумевает необходимость эффективной совместной работы на благо общества [23, c. 154]. Деятельность этнических общественных объединений в системе национальной безопасности страны будет положительной, если данные организации будут участвовать в реализации социальных и культурных программ федерального, регионального и муниципального уровней, а также в решении актуальных задач в области межнациональных отношений, профилактики и разрешения межэтнических конфликтов [1, с. 18]. Социальная практика показывает, что участие в межгосударственном и межрегиональном сотрудничестве, а также в переговорном процессе являются эффективными мероприятиями по предотвращению и урегулированию напряженности в межэтнических отношениях.

Свое концептуальное осмысление получили проблемы роли религиозных организаций в деле обеспечения национальной безопасности [18, с. 12]. Как отмечает А.Г. Нестерова, «повышение активности религиозных объединений вызвано либеральными реформами конца XX в., которые обозначили вектор дальнейшего развития гражданского общества в России, а также определили характер взаимоотношений между его институтами и органами государственной власти» $[17$, с. 132]. Исследователи обращают внимание на то, что они способны принимать активное участие в реализации задач обеспечения безопасности государства. И в качестве аргументов приводят исторические факты, свидетельствующие о позитивной роли церкви в годы Великой Отечественной войны [13, с. 76]. Они призывают к «деприватизации религии, предполагающей активное включение религиозных объедине- 
ний в жизнь общества» $[15$, с. 41$]$. Предотвращение или защита от угрозы межконфессиональной розни, осуществляемые религиозными общественными организациями, являются одними из важнейших задач обеспечения национальной безопасности. Если фактор мультиконфессиональности и не будет самостоятельно генерировать напряженность в обществе, то есть внешние силы, являющиеся геополитическими конкурентами или даже противниками нашего государства, стремящиеся разжечь межконфессиональные конфликты, чтобы в своих интересах воспользоваться их деструктивными последствиями для нашей страны [8, с. 22]. Необходимость обеспечения морально-политического единства граждан в условиях, когда оно относится к разным конфессиям, будет подталкивать государство к тому, чтобы базировать свою идеологию на надконфессиональных началах в соответствии с Конституцией и не позволить сделать какую-либо религию де-факто государственной, поскольку это может привести к расколу страны.

Отмечая роль социально ориентированных НКО как института сферы обеспечения национальной безопасности, исследователи указывают на тот факт, что через данные организации население доносит свои требования до органов власти [7, с. 42]. Как субъекты гражданского общества они способны оперативно реагировать на острые социально-экономические проблемы населения, представлять интересы различных социальных групп и благодаря механизмам общественного контроля оказывать влияние на работу представителей органов власти. В сфере реализации социальной политики данные организации, как правило, осуществляют комплекс мер, направленных на оказание помощи социально незащищенным слоям населения. Эти меры способствуют смягчению и преодолению тяжелых жизненных условий граждан, поддерживают их социальный статус, тем самым обеспечивая национальную безопасность. Следует согласиться с оценкой, что некоммерческие организации разрабатывают и достаточно эффективно реализуют социальные программы в зависимости от конкретных нужд различных групп населения [25, с. 93]. Ведь НКО оказывается существенная помощь гражданам, для которых создаются социальные службы, кризисные центры, приюты, группы самопомощи, ресурсные и молодежные центры, благотворительность и т. д. Внедрение данных организаций в систему национальной безопасности является важным условием ее совершенствования. Необходимо, чтобы государство создало благоприятные условия для данного типа общественных объединений, поскольку это позволит улучшить социально-политическую ситуацию в российском обществе.

Национальная безопасность России напрямую зависит от уровня участия граждан в политических процессах, но только при условии, что они не выходят за рамки конституционно-правового поля. Политологи А.Г. Иванова и И.М. Бояршинова обращают особое внимание на то, что «властные режимы демократического толка подразумевают сопричастность граждан формальным и неформальным политическим процессам посредством политического участия, которое выражается в таких политических феноменах, как политическая активность, политическая деятельность, политическое поведение и т. д.» $[10$, с. 64]. Государственная власть должна стремиться направить активность граждан в конструктивное русло и ни в коем случае не игнорировать или, более того, пытаться ее нивелировать. Следует согласиться с позицией исследователей, что задача, стоящая перед органами власти и обществом, заключается в том, чтобы, активизируя диалог власти с институтами гражданского общества по направлениям обеспечения национальной безопасности, направить политическую активность граждан в созидательное русло [3, с. 82].

Очевидно, что партии и общественнополитические движения разных форм и типов оказывают существенное влияние на состояние системы национальной безопасности России. Причем это влияние может быть как позитивным и, соответственно, поддерживать стабильность государственно-политической системы, так и направленным на ее дестабилизацию [21, с. 27]. Следует отметить, что альтернативные направленности общественно-политических движений являются ответной реакцией на реализуемый в стране политический курс не только самих граж- 
дан, но и внешних сил, заинтересованных в изменении политического курса страны. Тем не менее не следует все оппозиционные общественно-политические движения однозначно толковать как деструктивные. Через диалектическое отрицание того, что мешает обществу эффективно функционировать, и возможна стабильность его политической системы. Это не распространяется на идеологические и политические течения радикальной направленности, основной задачей которых является не легальное устранение недостатков существующего политического режима, а создание в стране хаоса, представляющего серьезную угрозу существованию российского суперэтноса.

В российском обществе отчетливо наблюдается рост заинтересованности молодежи политикой, теми важными процессами, которые в ней происходят [20, с. 352]. Поэтому становится все более заметной активизация политической деятельности молодежных общественных организаций, которая находит свое выражение в непосредственном их участии в политических событиях, происходящих в обществе. Повышение информированности о политической обстановке обусловливает изменение образа мысли молодежи, уменьшается ее конформизм, переосмысливается стереотипный взгляд на многие проблемы. Политическая активизация молодежи опосредованно связана с состоянием национальной безопасности в России. Ведь молодежь представляет стратегический и тактический ресурс не только для правящего режима, но и для представителей оппозиционных сил. С одной стороны, она может своей политической активностью поддерживать политическую систему, обеспечивая ее устойчивое развитие, тем самым, укрепляя национальную безопасность страны, а с другой - может стать источником дестабилизации общественно-политической системы, оказавшись под влиянием чуждых национальным интересам сил, финансируемой компрадорской олигархией. Следует согласиться с позицией С.А. Мосоликова, что наиболее важной задачей в контексте поднятой проблематики является приобщение молодежи к политике через институционализированные формы ее участия [16, с. 159].
Анализируя механизмы взаимодействия органов власти и молодежных общественнополитических объединений в области обеспечения национальной безопасности, В.А. Крючков и А.Е. Москалев определяют наиболее распространенные формы участия данных движений в российском политическом процессе, которые позволяют выразить целый спектр политических взглядов молодежи: членство в молодежных парламентских органах, молодежных правительствах, обсуждение законотворческих инициатив, участие и создание «медийных» общественно-политических кампаний, массовых акций, проведение форумов, круглых столов, на которых обсуждаются значимые общественные и политические проблемы и вопросы, связанные с обеспечением национальной безопасности [11, с. 176-177]. Молодежный парламент как одна из технологий гражданского участия в процессе принятия социально-политических решений может служить эффективным инструментом политической социализации, способствующим укреплению национальной безопасности. О.Н. Ванеев высоко оценивает его потенциал: «...он представляется сегодня необходимостью, поскольку именно с развитием данного института гражданского общества все остальные формы участия в политическом процессе сложатся в стройную систему и позволят трансформировать деятельность молодежи в указанном направлении из эпизодической в стабильную и размеренную» [2, с. 117].

Таким образом, российские исследователи придают большое значение взаимодействию институтов государства и гражданского общества в деле обеспечения национальной безопасности РФ, концептуально обосновывая необходимость их совместной деятельности в этом направлении. Они признают, что данный потенциал реализуется еще далеко не в полной мере. Можно выделить два основных концептуальных подхода (либеральный и этатистский), к которым тяготеют отечественные исследователи. Сторонники либерального подхода выступают за доминирование интересов институтов гражданского общества в процессе развития системы национальной безопасности и за их равноправное сотрудничество с государственными структурами. Приверженцы этатистской концепции отстаи- 
вают безусловный приоритет государственных органов в формировании системы национальной безопасности.

\section{СПИСОК ЛИТЕРАТУРЫ}

1. Баймлер, О. Р. Национально-культурная автономия в системе технологий предотвращения и урегулирования внутригосударственных конфликтов : автореф. дис. ... канд. полит. наук / Баймлер Олег Райнгольдович. - М., 2013. - 24 с.

2. Ванеев, О. Н. Молодежные парламенты как институт муниципальной демократии в Российской Федерации / О. Н. Ванеев // Право и образование. 2009. - № 9. - C. 114-121.

3. Власенко, Л. В. К вопросу о взаимодействии молодежных организаций с государственной властью / Л. В. Власенко // Социальное развитие современного российского общества: достижения, проблемы, перспективы. -2009. - № 1. - С. 78-86.

4. Возженников, А. В. Глобальные вызовы, угрозы и опасности современности. Приоритеты политики обеспечения национальной безопасности России / А. В. Возженников. - М. : Изд-во Рос. акад. гос. службы при Президенте Российской Федерации, 2008. - $161 \mathrm{c}$.

5. Вырщиков, А. Н. Стратегия научных исследований феномена патриотизма и патриотического воспитания молодежи / А. Н. Вырщиков, М. Б. Кусмарцев. - Волгоград : ПринтТерра, 2007. - 172 с.

6. Государство и гражданское общество в России: новые практики взаимодействия / А. А. Пронин, Д. С. Агалин, А. А. Акмалова [и др.]. - Волгоград : Волгогр. науч. изд-во, 2013. - 779 с.

7. Грищенко, Ю. И. Межсекторное социальное партнерство: НКО, государство, бизнес / Ю. И. Грищенко // Некоммерческие организации в России. 2014. - № 5. - C. 39-45.

8. Дринова, Е. М. Многообразие моделей модернизации и политизации религии: теоретические и практические аспекты / Е. М. Дринова, С. А. Панкратов // Право и политика. -2015. - № 1. - С. 19-24.

9. Ефанова, Е. В. Обеспечение стабильности функционирования политической системы Российской Федерации в условиях модернизационного прорыва / Е. В. Ефанова, С. А. Панкратов // Известия Саратовского университета. Серия: Социология. Политология. - 2014. - № 1. - С. 83-88.

10. Иванова, А. Г. Политические партии и общественные организации как элементы гражданского общества: современные реалии и перспективы / А. Г. Иванова, И. М. Бояршинова. - Оренбург : Изд-во ОГПУ, 2012. - 205 с.

11. Крючков, В. А. Активизация молодежных общественно-политических объединений в начале
XXI века / В. А. Крючков, А. Е. Москалев // PolitBook. 2014. - № 2. - C. 168-189.

12. Марутин, А. Г. К вопросу о причинноследственной связи появления в отечественном законодательстве нормы о «иностранных агентах» / А. Г. Марутин // Известия Сочинского государственного университета. - 2014. - № 1. - С. 21-222.

13. Меньшикова, Н. С. Религиозные организации - институт гражданского общества воюющего государства: вклад в победу в Великой Отечественной войне / Н. С. Меньшикова // Великая Отечественная война: нравственные аспекты и историческое наследие : материалы всерос. науч.теорет. конф. молодых исследователей. - СПб. : Издво Санкт-Петербург. ун-та МВД России, 2015. C. 75-76.

14. Микрюков, В. О. Проблемы национальной безопасности и гражданского общества глазами экспертов / В. О. Микрюков // ГосРег: государственное регулирование общественных отношений. 2012. - №2. - С. 226-229.

15. Морозова, И. Н. Феномен религии в гражданском обществе: европейский «тіх» на конференции в Стокгольме / И. Н. Морозова // Вестник Челябинской государственной академии культуры и искусств. -2010 . - № 2. - С. 39-47.

16. Мосоликов, С. А. Развитие и деятельность молодежных общественно-политических объединений в современной России / С. А. Мосоликов // Исторические, философские, политические и юридические науки, культурология и искусствоведение. Вопросы теории и практики. - 2015. - №2. - С. 158-162.

17. Нестерова, А. Г. Религиозные организации в условиях становления гражданского общества / А. Г. Нестерова // Власть. - 2010. - № 12. C. 130-134.

18. Опарин, А. Ю. Деятельность религиозных организаций как фактор становления гражданского общества в России : автореф. дис. ... канд. филос. наук / Опарин Алексей Юрьевич. - Ростов н/Д., 2007. - 36 с.

19. Панкратов, С. А. Государство и гражданское общество в поисках инновационных ресурсов преодоления ксенофобии, национализма и экстремизма в современной России / С. А. Панкратов, С. И. Морозов // Вестник Волгоградского государственного университета. Серия 4, История. Регионоведение. Международные отношения. - 2013. № 1. - C. 149-150.

20. Панкратов, С. А. Модернизация России: проблемы обеспечения безопасности в глобальном мире / С. А. Панкратов // Военная история России: проблемы, поиски, решения : материалы Междун. науч. конф., посвящ. 70-летию Победы в Великой Отечественной войне. - Волгоград : Изд-во ВолГУ, 2015. - C. 350-360. 
21. Семченков, А. С. Противодействие современным угрозам политической стабильности в системе обеспечения национальной безопасности России : автореф. дис. ... д-ра полит. наук / Семченков Андрей Сергеевич. -М. : Изд-во МГУ, 2012. - 50 с.

22. Соколова, С. Н. Демократизация сферы безопасности: российская власть и гражданское общество / С. Н. Соколова, А. А. Соколова // Проблемы безопасности российского общества. - 2012. № 1. - С. 98-107.

23. Сулейманов, А. 3. Роль общественных организаций в формировании национального самосознания / А. 3. Сулейманов // Историческая и социально-образовательная мысль. - 2012. - № 1. C. $153-155$.

24. Шиловцев, А. В. Социальная безопасность в условиях глобализации: онтология проблемы / А. В. Шиловцев // Актуальные направления научных исследований XXI века: теория и практика. - 2013. - № 1. - С. 231-237.

25. Яблонский, В. Б. Новые тенденции, проблемы и поиски решений субъектами социального взаимодействия (власть - НКО - бизнес - высшая школа) / В. Б. Яблонский, Н. Ю. Сурова // Поволжский торгово-экономический журнал. 2014. - № 6. - С. 91-95.

\section{REFERENCES}

1. Baymler O.R. Natsionalno-kulturnaya avtonomiya $v$ sisteme tekhnologiy predotvrashcheniya i uregulirovaniya vnutrigosudarstvennykh konfliktov: avtoref. dis. ... kand. polit. nauk[National and Cultural Autonomy in the System of Technologies for Prevention and Settlement of the Interstate Conflicts. Cand. polit. sci. abs. diss.]. Moscow, 2013. 24 p.

2. Vaneev O.N. Molodezhnye parlamenty kak institut munitsipalnoy demokratii v Rossiyskoy Federatsii [Youth Parliaments as an Institute of Municipal Democracy in the Russian Federation]. Pravo i obrazovanie, 2009, no. 9, pp. 114-121.

3. Vlasenko L.V. K voprosu o vzaimodeystvii molodezhnykh organizatsiy s gosudarstvennoy vlastyu [On the Interaction of the Youth Organizations With the Government]. Sotsialnoe razvitie sovremennogo rossiyskogo obshchestva: dostizheniya, problemy, perspektivy, 2009, no. 1, pp. 78-86.

4. Vozzhennikov A.V. Globalnye vyzovy, ugrozy $i$ opasnosti sovremennosti. Prioritety politiki obespecheniya natsionalnoy bezopasnosti Rossii [Global Challenges, Threats and Dangers of the Present. Priorities of Policy for Ensuring National Security of Russia]. Moscow, Izd-vo Rossiyskoy akademii gosudarstvennoy sluzhby pri Prezidente Rossiyskoy Federatsii, 2008. 161 p.
5. Vyrshchikov A.N., Kusmartsev M.B. Strategiya nauchnykh issledovaniy fenomena patriotizma i patrioticheskogo vospitaniya molodezhi [Strategy of Scientific Research of the Phenomenon of Patriotism and Patriotic Education of Youth]. Volgograd, PrintTerra Publ., 2007. 172 p.

6. Pronin A.A., Agalin D.S., Akmalova A.A. Gosudarstvo $i$ grazhdanskoe obschestvo v Rossii: novye praktiki vzaimodejstviya [The State and Civil Society in Russia: New Practicians of Interaction]. Volgograd, Volgogr. nauchn. izd-vo, 2013. 779 p.

7. Grishchenko Yu.I. Mezhsektornoe sotsialnoe partnerstvo: NKO, gosudarstvo, biznes [Intersector Social Partnership: NPO, State, Business]. Nekommercheskie organizatsii v Rossii, 2014, no. 5, pp. 39-45.

8. Drinova E.M., Pankratov S.A. Mnogoobrazie modeley modernizatsii i politizatsii religii: teoreticheskie i prakticheskie aspekty [Variety of Models of Modernization and Politicization of Religion: Theoretical and Practical Aspects]. Pravo i politika, 2015, no. 1, pp. 19-24.

9. Efanova E.V. Obespechenie stabilnosti funktsionirovaniya politicheskoiy sistemy Rossiyskoy Federatsii v usloviyah modernizatsionnogo proryva [Ensuring Stability of Functioning of Political System of the Russian Federation in the Conditions of Modernization Breakthrough]. Izvestiya Saratovskogo universiteta. Seria: Sotsiologiya. Politologiya, 2014, no. 1, pp. 83-88.

10. Ivanova A.G. Politicheskie partii $i$ obschestvennye organizatsii kak elementy grazhdanskogo obschestva: sovremennye realii $i$ perspektivy [Political Parties and Public Organizations as Elements of Civil Society: Modern Realities and Prospects]. Orenburg, Izd-vo OGPU, 2012. 205 p.

11. Kryuchkov V.A. Aktivizatsiya molodezhnykh obshchestvenno-politicheskikh obyedineniy v nachale XXI veka [Activization of Youth Political Associations at the Beginning of the 21st Century]. PolitBook, 2014, no. 2, pp. 168-189.

12. Marutin A.G. K voprosu o prichinnosledstvennoy svyazi poyavleniya $\mathrm{v}$ otechestvennom zakonodatelstve normy o "inostrannykh agentakh" [On the Emergence of Cause and Effect Relationship in the Domestic Legislation of the Norm on "Foreign Agents"]. Izvestiya Sochinskogo gosudarstvennogo universiteta, 2014, no. 1, pp. 216-222.

13. Menshikova N.S. Religioznye organizatsiiinstitut grazhdanskogo obshchestva voyuyushchego gosudarstva: vklad v pobedu v Velikoy Otechestvennoy voyne [The Religious Organizations - Institute of Civil Society of the Warring State: a Contribution to a Victory in the Great Patriotic War]. Velikaya Otechestvennaya voyna: nravstvennye aspekty $i$ istoricheskoe nasledie: materialy vserossiyskoy nauchno- 
prakticheskoy konferentsii molodykh issledovateley [The Great Patriotic War: Ethical Aspects and Historical Heritage: Proceedings of Scientific and Practical Conference of Young Researchers]. Saint Petersburg, Izd-vo Sankt-Peterburg. un-ta MVD Rossii, 2015, pp. 75-76.

14. Mikryukov V.O. Problemy natsionalnoy bezopasnosti i grazhdanskogo obshchestva glazami ekspertov [Problems of National Security and Civil Society From the Experts's Point of View]. GosReg: gosudarstvennoe regulirovanie obschestvennykh otnosheniy, 2012, no. 2, pp. 226-229.

15. Morozova I.N. Fenomen religii v grazhdanskom obshchestve: evropeyskiy "mix" na konferentsii v Stokgolme [Religion Phenomenon in Civil Society: European "Mix" at Conference in Stockholm]. Vestnik Chelyabinskoy gosudarstvennoy akademii kultury $i$ iskusstv, 2010, no. 2, pp. 39-47.

16. Mosolikov S.A. Razvitie i deyatelnost molodezhnykh obshchestvenno-politicheskikh obyedineniy v sovremennoy Rossii [Development and Activity of Youth Political Associations in Modern Russia]. Istoricheskie, filosofskie, politicheskie $i$ yuridicheskie nauki, kulturologiya i iskusstvovedenie. Voprosy teorii i prasktiki, 2015, no. 2, pp. 158-162.

17. Nesterova A.G. Religioznye organizatsii v usloviyakh stanovleniya grazhdanskogo obshchestva [The Religious Organizations in the Conditions of Civil Society Formation]. Vlast, 2010, no. 12, pp. 130-134.

18. Oparin A.Yu. Deyatelnost religioznykh organizatsiy kak faktor stanovleniya grazhdanskogo obshchestva $v$ Rossii: avtoref. dis. ... kand. filos. nauk [Activity of the Religious Organizations as a Factor of Civil Society Formation in Russia. Cand. philos. sci. abs. diss.]. Rostov-on-Don, 2007. 36 p.

19. Pankratov S.A. Gosudarstvo i grazhdanskoe obshchestvo $\mathrm{v}$ poiskakh innovatsionnykh resursov preodoleniya ksenofobii, natsionalizma i ekstremizma v sovremennoy Rossii [The State and Civil Society in Search of Innovative Resources of Overcoming Xenophobia, Nationalism and Extremism in Modern Russia]. Vestnik Volgogradskogo gosudarstvennogo universiteta. Seriya 4, Istoriya. Regionovedenie, Mezhdunarodnye otnosheniya [Science Journal of
Volgograd State University. History. Area Studies. International Relations], 2013, no. 1, pp. 149-150.

20. Pankratov S.A. Modernizatsiya Rossii: problemy obespecheniya bezopasnosti v globalnom mire [Modernization of Russia: Safety Problems in the Global World]. Voennaya istoriya Rossii: problemy, poiski, resheniya: materialy Mezhdunarodnoy nauchnoy konferentsii, posvyashchennoy 70-letiyu Pobedy $v$ Velikoy Otechestvennoy voyne [Military History of Russia: Problems, Searches, Solutions: Proceedings of Internatonal Scientific Conference, Dedicated to the 70th Anniversary of Victory in the Great Patriotic War]. Volgograd, Izd-vo VolGU, 2015, pp. 350-360.

21. Semchenkov A.S. Protivodeystvie sovremennym ugrozam politicheskoy stabilnosti $v$ sisteme obespecheniya natsional'noy bezopasnosti Rossii: avtoref. dis. ... d-ra polit. nauk [Counteraction to Modern Threats to Political Stability in the System of Ensuring National Security of Russia. Dr. polit. sci. abs. diss.]. Moscow, Izd-vo MGU, 2012. 50 p.

22. Sokolova S.N. Demokratizatsiya sfery bezopasnosti: rossiyskaya vlast i grazhdanskoe obshchestvo [Democratization of the Sphere of Safety: Russian Power and Civil Society]. Problemy bezopasnosti rossiyskogo obshchestva, 2012, no. 1, pp. 98-107.

23. Suleymanov A.Z. Rol obshchestvennykh organizatsiy v formirovanii natsionalnogo samosoznaniya [The Role of Public Organizations in Formation of National Consciousness]. Istoricheskaya i sotsialnoobrazovatelnaya mysl, 2012, no. 1, pp. 153-155.

24. Shilovtsev A.V. Sotsialnaya bezopasnost v usloviyakh globalizatsii: ontologiya problemy [Social Safety in the Conditions of Globalization: Problem Ontology]. Aktualnye napravleniya nauchnykh issledovaniy XXI veka: teoriya i praktika, 2013, no. 1, pp. 231-237.

25. Yablonskiy V.B. Novye tendentsii, problemy i poiski resheniy subyektami sotsialnogo vzaimodeystviya (vlast - NKO - biznes - vysshaya shkola) [New Tendencies, Problems and Searches of Decisions by the Subjects of Social Interaction (Power - NPO - Business Higher School)]. Povolzhskiy torgovo-ekonomicheskiy zhurnal, 2014, no. 6, pp.91-95. 


\section{Information About the Authors}

Vyacheslav N. Gulyaikhin, Doctor of Sciences (Philosophy), Professor, Head of Department of Social Work and Pedagogy, Volgograd State University, Prosp. Universitetsky, 100, 400062 Volgograd, Russian Federation, gulyaich@yandex.ru, srm@volsu.ru.

Pavel P. Fantrov, Postgraduate Student, Specialist of Education and Methodology, Department of Social Work and Pedagogy, Volgograd State University, Prosp. Universitetsky, 100, 400062 Volgograd, Russian Federation, pavelfantrov@,rambler.ru, srm@,volsu.ru.

\section{Информация об авторах}

Вячеслав Николаевич Гуляихин, доктор философских наук, профессор, заведующий кафедрой социальной работы и педагогики, Волгоградский государственный университет, просп. Университетский, 100, 400062 г. Волгоград, Российская Федерация, gulyaich@yandex.ru, srm@,volsu.ru.

Павел Петрович Фантров, аспирант, специалист по учебно-методической работе кафедры социальной работы и педагогики, Волгоградский государственный университет, просп. Университетский, 100, 400062 г. Волгоград, Российская Федерация, pavelfantrov@rambler.ru, srm@volsu.ru. 